\title{
Strategies to Modulate the Redifferentiation of Chondrocytes
}

\author{
Xiaoshen $\mathrm{Hu}^{1 \dagger}$, Weiyang Zhang ${ }^{2 \dagger}$, Xiang $\mathrm{Li}^{3 \dagger}$, Dongling Zhong ${ }^{1}$, Yuxi $\mathrm{Li}^{3}$, Juan $\mathrm{Li}^{1 *}$ and \\ Rongjiang $\mathrm{Jin}^{1 *}$
}

${ }^{1}$ School of Health Preservation and Rehabilitation, Chengdu University of Traditional Chinese Medicine, Chengdu, China, ${ }^{2}$ Shool of Sports Medicine and Health, Chengdu Sport University, Chengdu, China, ${ }^{3}$ School of Acupuncture-Moxibustion and Tuina, Chengdu University of Traditional Chinese Medicine, Chengdu, China

\section{OPEN ACCESS}

Edited by:

Chao Zhao,

University of Alabama, United States

Reviewed by:

Xiaoran $\mathrm{Li}$,

Donghua University, China

Dongfang Zhou,

Southern Medical University, China

*Correspondence:

Juan Li

785939016@qq.com

Rongjiang Jin

cdzyydxirj@126.com

tThese authors have contributed equally to this work and share first authorship.

Specialty section:

This article was submitted to Biomaterials,

a section of the journal Frontiers in Bioengineering and Biotechnology

Received: 25 August 2021 Accepted: 01 November 2021 Published: 22 November 2021

Citation:

HuX, Zhang W, LiX, Zhong D, LiY, LiJ and Jin $R$ (2021) Strategies to Modulate the Redifferentiation of Chondrocytes.

Front. Bioeng. Biotechnol. 9:764193. doi: 10.3389/fbioe.2021.764193
Because of the low self-healing capacity of articular cartilage, cartilage injuries and degenerations triggered by various diseases are almost irreversible. Previous studies have suggested that human chondrocytes cultured in vitro tend to dedifferentiate during the cell-amplification phase and lose the physiological properties and functions of the cartilage itself, which is currently a critical limitation in the cultivation of cartilage for tissue engineering. Recently, numerous studies have focused on the modulation of chondrocyte redifferentiation. Researchers discovered the effect of various conditions (extracellular environment, cell sources, growth factors and redifferentiation inducers, and gene silencing and overexpression) on the redifferentiation of chondrocytes during the in vitro expansion of cells, and obtained cartilage tissue cultured in vitro that exhibited physiological characteristics and functions that were similar to those of human cartilage tissue. Encouragingly, several studies reported positive results regarding the modulation of the redifferentiation of chondrocytes in specific conditions. Here, the various factors and conditions that modulate the redifferentiation of chondrocytes, as well as their limitations and potential applications and challenges are reviewed. We expect to inspire research in the field of cartilage repair toward the future treatment of arthropathy.

Keywords: chondrocytes, redifferentiation, dedifferentiation, cartilage tissue engineering, arthropathy

\section{INTRODUCTION}

A multitude of diseases, such as osteoarthritis and trauma, lead to the degeneration and defect of articular cartilage; because articular cartilage hardly repairs itself, the loss of articular cartilage implies that these patients would have limited mobility and even disability (Smolen et al., 2016; Krishnan and Grodzinsky, 2018). Researchers have attempted to repair cartilage using a variety of techniques. The most recognized among them is autologous chondrocyte implantation (ACI), which uses autologous chondrocytes that are cultured and expanded in vitro for repairing cartilage by transplanting the expanded chondrocytes or cartilage-like tissue shaped using tissue-engineering technology into joints. However, one major problem of $\mathrm{ACI}$ is that autologous chondrocytes would dedifferentiate during the process of proliferation in vitro, become fibrous-like cells, and lose the physiological characteristics of the chondrocytes themselves. Therefore, researchers aim to develop methods to solve this problem and have assessed a variety of factors and techniques that may regulate the redifferentiation of chondrocytes in vitro, including the extracellular environment, cell sources, growth factors and redifferentiation inducers in the cell culture environment, and gene silencing and overexpression. In this study, we summarized and analyzed relevant studies in this field to provide strategies for the modulation of chondrocyte redifferentiation. 
TABLE 1 | Cell source modulates the redifferentiation of chondrocytes.

\begin{tabular}{|c|c|c|c|}
\hline Aspects & Factors & $\begin{array}{l}\text { Modulation of chondrocyte } \\
\text { redifferentiation }\end{array}$ & References \\
\hline \multirow[t]{4}{*}{$\begin{array}{l}\text { Cell } \\
\text { source }\end{array}$} & Human knee chondrocytes & Commonly used cell sources & $\begin{array}{l}\text { Jones and Peterson, (2006); Minas et al., (2014); Mistry et al., } \\
\text { (2017) }\end{array}$ \\
\hline & $\begin{array}{l}\text { Human nasal septal } \\
\text { chondrocytes }\end{array}$ & $\begin{array}{l}\text { Better reproducible ability to generate hyaline-like cartilage } \\
\text { tissue }\end{array}$ & Mumme et al., (2016); von Bomhard et al., (2017) \\
\hline & $\begin{array}{l}\text { Human polydactyly } \\
\text { chondrocytes }\end{array}$ & Potential for stable cartilage production & Cavalli et al. (2019) \\
\hline & Human microtia chondrocytes & 3D chondrogenic culture system is needed & He et al. (2020) \\
\hline
\end{tabular}

\section{CELL SOURCES}

The main cell source of ACI is a cartilage sample from the lowweight-bearing area of the patient's sick joint (mainly the knee joint), which provides chondrocytes for cultivation and expansion in vitro, followed by their implantation into the articular cartilage defect (Jones and Peterson, 2006; Minas et al., 2014; Mistry et al., 2017). Current research shows that chondrocytes extracted from articular hyaline cartilage remain more effective in repairing cartilage than human bone marrow stem cells (HBMSCs), even though the former usually undergo dedifferentiation during in vitro culture and expansion (Makris et al., 2015). The implantation of HBMSCs into the defect of articular cartilage usually causes the formation of fibrocartilage, which is not sufficient for joints that have weight-bearing functions.

In turn, the use of human nasal septal chondrocytes in ACI has better clinical application potential (Mumme et al., 2016; von Bomhard et al., 2017). Compared with articular cartilage cells, human nasal septum chondrocytes exhibit a superior ability to reproducibly generate hyaline-like cartilage tissues, based on their plasticity of adaption to a joint environment. Moreover, polydactyly cartilage derived from patients with polydactyly in infancy may be another option in this setting. Polydactyly chondrocytes also have the potential for use in stable cartilage production (Cavalli et al., 2019). Similarly, microtia chondrocytes from patients with microtia are another alternative cell source, as dedifferentiated microtia chondrocytes transform into redifferentiated microtia chondrocytes after culturing in a three-dimensional (3D) chondrogenic culture system (He et al., 2020). Relevant researches on cell source have been summarized in Table 1.

For practical application, it is feasible to use cartilage tissue from the patient's own diseased joint as a cell source for ACI. However, the state of articular cartilage cells in different patients is not the same. Therefore, the reproducibility of the results of this approach in different studies is questionable.

\section{EXTRACELLULAR MICROENVIRONMENT}

During the process of in vitro expansion of chondrocytes, a variety of extracellular microenvironmental conditions may affect their dedifferentiation and redifferentiation, including the culture temperature, hypoxia, 3D culture, extracellular matrix (ECM), and hydrogel. Several studies have confirmed that hypoxia and
3D culture are beneficial for the redifferentiation of chondrocytes. Because 3D culture lacks uniform standards, the quality of studies of $3 \mathrm{D}$ culture is inconsistent. In turn, the fact that a low temperature $\left(32.2^{\circ} \mathrm{C}\right)$ delays the dedifferentiation of chondrocytes may be because it attenuates all biological processes in chondrocytes. Finally, hydrogels have great potential for the redifferentiation of chondrocytes; however, the related parameter standard of hydrogels requires further investigation.

\section{Culture Temperature}

In $3 \mathrm{D}$ pellet culture, a temperature of $37^{\circ} \mathrm{C}$ promotes chondrocyte redifferentiation to a greater extent than does a temperature of $32.2^{\circ} \mathrm{C}$. Moreover, a temperature of $32.2^{\circ} \mathrm{C}$ slows down the proliferation rate of chondrocytes significantly. In monolayer culture, hypothermia at $32.2^{\circ} \mathrm{C}$ retarded the dedifferentiation and proliferation rate of chondrocytes significantly (von Bomhard et al., 2017). Hypothermia has the potential to avoid dedifferentiation in monolayer culture. Another study demonstrated that a culture temperature of $41^{\circ} \mathrm{C}$ inhibited the redifferentiation of chondrocytes and the formation of ECM compared with $37^{\circ} \mathrm{C}$ (Ito et al., 2015).

\section{Hypoxia}

The environment in human healthy joints is hypoxic with negative pressure (Stegen et al., 2019). Does hypoxia regulate the redifferentiation of chondrocytes? Many studies (Duval et al., 2009; Markway et al., 2013; Das et al., 2015; Ollitrault et al., 2015; Rakic et al., 2017; Öztürk et al., 2017; Jeyakumar et al., 2019) have investigated the effect of hypoxic conditions on the redifferentiation of chondrocytes during in vitro expansion, with the results basically indicating that hypoxia has a positive effect on the redifferentiation of chondrocytes. In addition, several studies have reported that a partial oxygen pressure $\left(\mathrm{pO}_{2}\right)$ of $2.5 \%$ achieves the best effect in improving the expression of chondrocytic markers (Acan and Col2al) and suppressing the expression of dedifferentiation markers (Colla1 and Col3a1) (Jahr et al., 2019).

\section{Three-Dimensional Culture}

At present, 3D culture is widely used in cell culture, because researchers increasingly find that the extracellular environment of $2 \mathrm{D}$ culture is far from the real extracellular microenvironment. 3D culture can be classified into 3D culture methods with and without scaffolds (Wu X. et al., 


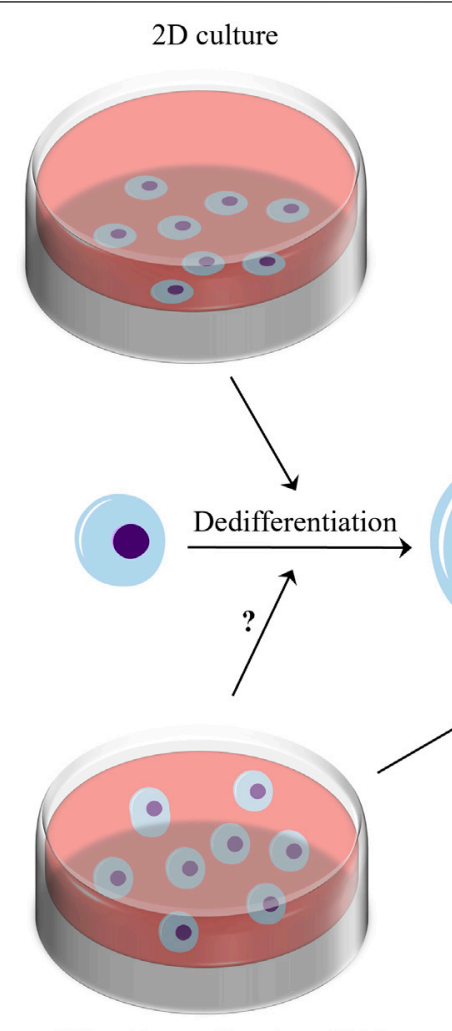

3D culture without scaffold
3D culture with scaffold
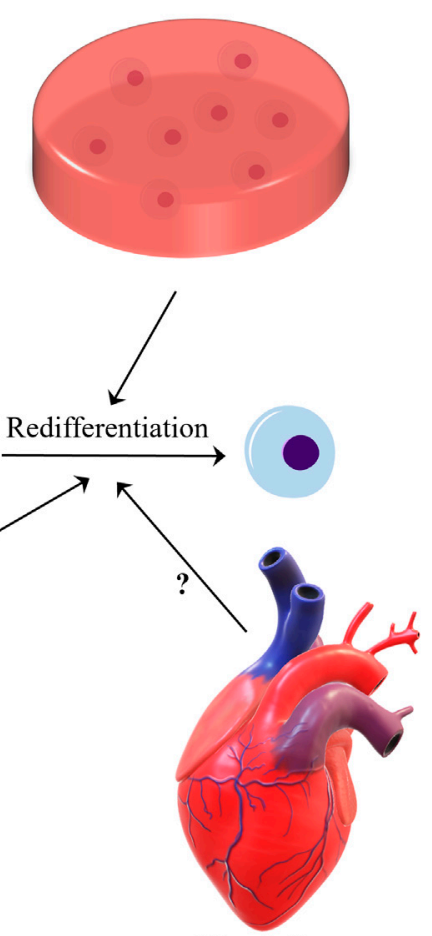

Bioprinting

FIGURE 1 | In the microenvironment of two-dimensional culture, chondrocytes generally undergo dedifferentiation after proliferation. Three-dimensional culture with scaffolds has a good ability to modulate the redifferentiation of chondrocytes. And does the three-position culture without scaffold and bioprinting have the ability to modulate the redifferentiation of chondrocytes? This issue needs further research to clarify.

2021), and Three-dimensional culture with scaffolds is widely used to redifferentiate chondrocytes (Caron et al., 2012). This type of culture is a common approach that is used to induce and maintain chondrocyte redifferentiation, and generate ECM. Numerous studies (von Bomhard et al., 2017; He et al., 2020; Caron et al., 2012; Takahashi et al., 2007; Schulze-Tanzil, 2009; Mukaida et al., 2005; Ahmed et al., 2014) have shown that $3 \mathrm{D}$ culture with scaffolds can regulate the redifferentiation of chondrocytes. Perhaps because researchers generally believe that $3 \mathrm{D}$ culture with scaffolds is closer to mammalian cartilage in physical properties, almost all 3D cultures with scaffolds are used to regulate chondrocyte redifferentiation. But can a scaffold-free $3 \mathrm{D}$ culture system regulate the redifferentiation of chondrocytes? This is a question worth studying. The application of bioprinting in cartilage tissue engineering has made great progress, but its effect on the redifferentiation of chondrocytes needs further research (Han et al., 2021). Besides, there is no criterion for $3 \mathrm{D}$ culture, which hinders its application to the induction of the redifferentiation of chondrocytes (represented in Figure 1).

\section{Extracellular Matrix and Hydrogels}

It is believed that $3 \mathrm{D}$ culture can induce chondrocyte differentiation. Researchers have explored many bionic materials in this context. Because of the wide range of feasible properties and the ability to culture cells in material, hydrogels have become a promising extracellular scaffold (Vega et al., 2017). Based on their ability to adjust their elasticity, hydrogels are an option to regulate the redifferentiation of chondrocytes (Bachmann et al., 2020). Fibrin hydrogels with elasticity close to $30 \mathrm{kPa}$ have a shape that is similar to that of the natural physiological cartilage tissue and is able to induce the synthesis of physiological ECM constituents, such as glycosaminoglycans (sGAG) and collagen type II (Bachmann et al., 2020). In addition, the adhesion-site density of the hydrogels has been proven to affect the redifferentiation of chondrocytes, whereas the hardness of the hydrogel substrate does not (Schuh et al., 2012). Researchers have discovered several novel types of hydrogel for the proliferation of chondrocytes in vitro. For example, a microcavitary alginate hydrogel can help dedifferentiated chondrocytes to redifferentiate and recover the capability of synthesizing ECM (Zeng et al., 2015). Gelatin-methacryloyl hydrogels, tyrosinase-crosslinked alginate sulfate tyramine hydrogels, and composite microfibers also exhibit potential for the engineering of cartilage-like tissues for 3D cultured chondrocytes (Klotz et al., 2016; Angelozzi et al., 2017; Öztürk et al., 2020). Self-assembled dendritic DNA hydrogel possesses inherent biocompatibility, biodegradability, and unique programmability, and has shown great potential in three- 


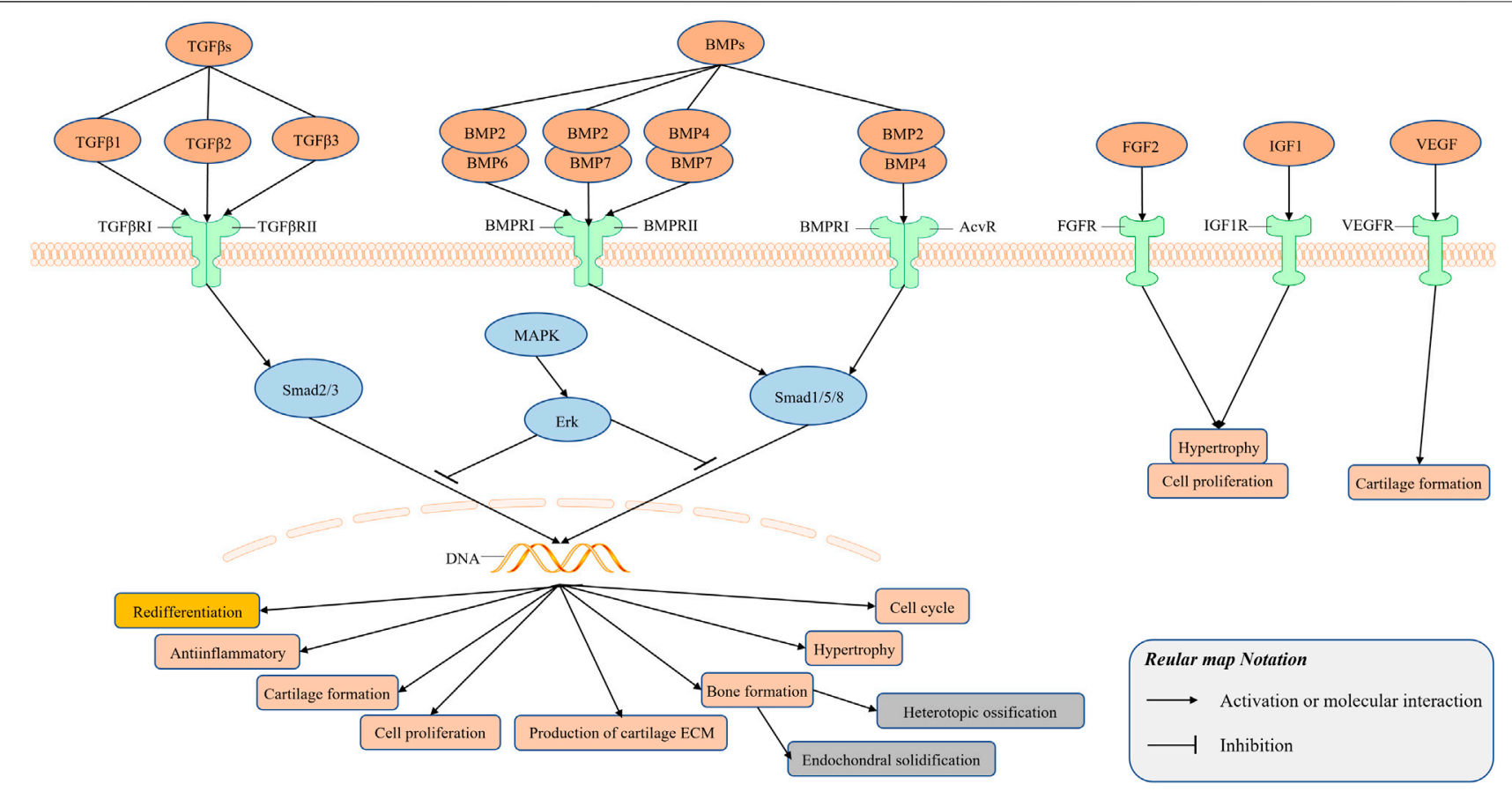

FIGURE 2 | Signal transduction mediated by growth factors plays an important role in the regulation of cell growth, differentiation and development in many biological systems. There exists cross-talk among the members of the TGF- $\beta$ superfamily to regulate the redifferentiation of chondrocytes. TGF $\beta$ s bind to its receptor TGF $\beta$ receptor I (TGF $\beta$ RI) and II (TGF $\beta$ RII) to form a complex, and BMPs bind to its receptor BMP receptor I (BMPRI) and II (BMPRII), Acv receptor (AcvR) to form a complex.

dimensional cell culture (Wu J. et al., 2021), but its effect on the redifferentiation of chondrocytes needs further investigation.

Compared with hydrogels, the decellularized matrix (DCM) derived from natural tissues is more suitable for cell culture and is closer to the physiological environment; however, the DCM has the disadvantage of being arduous to generate in large quantities. The mesenchymal stem cell (MSC)-derived extracellular matrix (MSCECM) is a natural biological material with strong bioactivity and excellent biocompatibility. Studies have shown that MSC-ECM derived from decellularized human bone marrow is an excellent culture substrate for the expansion of chondrocytes, with firm cartilage formation being observed after 21 days of culture in vitro (Yang et al., 2018). The meniscus-derived DCM has shown the promising effect of promoting the proliferation of chondrocytes. With the intervention of combined growth factors, meniscusderived DCM can modulate the differentiation of chondrocytes (Liang et al., 2020). In addition, ECM deposited by synovialderived stem cells significantly enhanced the proliferation of chondrocytes and retarded the dedifferentiation of the proliferated chondrocytes (Pei and He, 2012).

\section{Growth Factors and Redifferentiation Inducers}

Signal transduction mediated by the TGF $\beta$ superfamily plays an important role in the regulation of cell growth, differentiation, and development in many biological systems. The TGF $\beta$ and bone morphogenetic proteins (BMP) signaling pathways are regulated at multiple levels by the MAPK signaling pathway. In addition, in some cases, the TGF $\beta$ signaling pathway can also affect Smad-independent signal pathways, including the Erk, SAPK/JNK, and p38 MAPK signal pathways. Therefore, there exists cross-talk among the members of the TGF- $\beta$ superfamily to regulate the redifferentiation of chondrocytes. Some studies have demonstrated the positive effect of the combined application of growth factors on the regulation of redifferentiation, but it is difficult to ignore the negative effect of some growth factors on the repair of cartilage, such as BMP2 can induce endochondral solidification (Zhou et al., 2016) and BMP7 may induce heterotopic ossification (Spiro et al., 2010); therefore, additional research is needed to assess the combinatorial effect of different growth factors.

\section{Transforming Growth Factor $\beta$ Family}

Growth factors play a crucial role in the processes of cell proliferation, extracellular matrix synthesis, phenotype maintenance, induction of dedifferentiated chondrocytes or MSCs, and cartilage formation. The members of the transforming growth factor $\beta$ (TGF $\beta$ ) family are particularly paramount for these roles (Freyria and Mallein-Gerin, 2012; Dexheimer et al., 2016). Members of the TGF $\beta$ family include TGF $\beta$ s, BMPs, and growth and differentiation factors (GDFs) (Thielen et al., 2019). The TGF $\beta$ family regulates cell-fate decisions during development, and tissue homeostasis and regeneration. The members of the TGF $\beta$ family are major participants in 


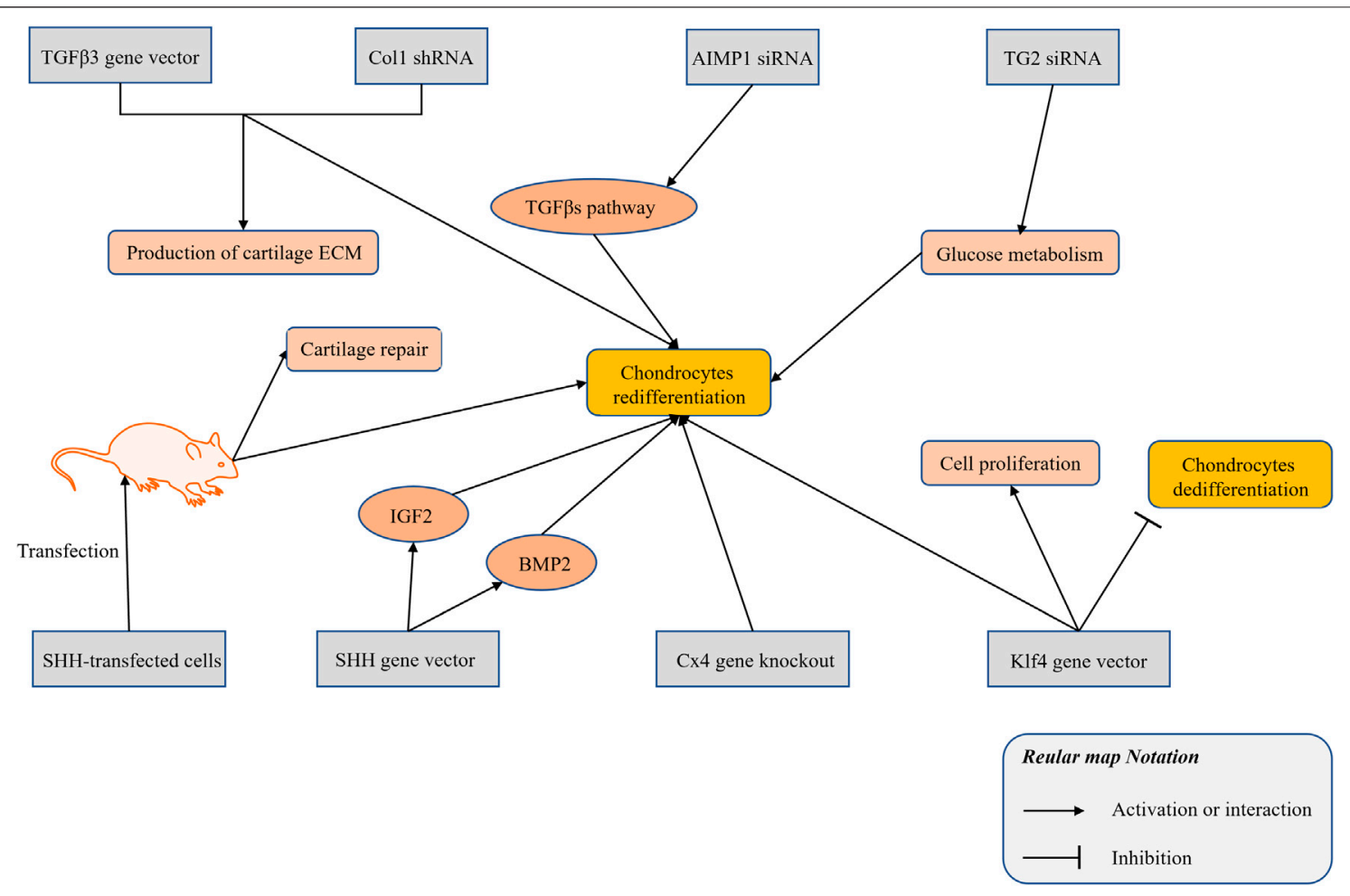

FIGURE 3 | The research progress of gene silencing and expression technology in modulating the chondrocytes redifferentiation.

cartilage and bone formation, tumorigenesis, fibrotic diseases, immune dysfunction, and various congenital diseases (Wozney et al., 1988; David and Massagué, 2018).

Humans express three types of TGF $\beta$, including TGF $\beta 1$, TGF $\beta 2$, and TGF 33 (Chen and Ten Dijke, 2016). TGF $\beta$ s are secreted by chondrocytes and combine with their ECM. Moreover, the TGF $\beta$ signaling pathways are related to the production and maintenance of cartilage ECM (van der Kraan et al., 1992; Jahr et al., 2019; Bachmann et al., 2020) and have a positive antiinflammatory effect in cartilage (Rédini et al., 1993; Takahashi et al., 2005). Of note, the regulation of chondrocyte hypertrophy is a particularly crucial role of TGF $\beta$ signaling pathways. The signaling transduction of pSMAD2/3 induced by TGF $\beta$ s blocks the hypertrophy and terminal differentiation of chondrocytes (Yang et al., 2001; Li et al., 2006; Blaney Davidson et al., 2009; Kim et al., 2012). In some studies, TGF $\beta$ s are used as a supplement to stimulate the redifferentiation of cultured chondrocytes in vitro (Jakob et al., 2001; Lee et al., 2005; van der Windt et al., 2010; Baugé et al., 2013; Bianchi et al., 2017; Bianchi et al., 2019). In contrast, the inhibition of the activity of TGF $\beta 1$ during cell expansion in vitro increases the redifferentiation ability of chondrocytes and inhibits their hypertrophy (Narcisi et al., 2012). TGF $\beta$ signaling transduction is pivotal in the regulation of the dedifferentiation and redifferentiation of chondrocytes (Dong et al., 2005). Nevertheless, this is a complex process, and additional research is necessary to clarify this issue.
In humans, the BMP signaling pathways include more than 20 distinct ligands, four type I receptors (Bmpr1a, Bmpr1b, Acvr1, and Alk1) and three type II receptors (Bmpr2, Acvr2a, and Acvr2b) (Antebi et al., 2017). These components can be combined with each other to assemble hundreds of different receptor-ligand complexes. Each complex is composed of two type I receptors and two type II receptor-binding ligands. The current research shows that the BMP pathway usually operates through multiple ligands and receptors (Lorda-Diez et al., 2014; Salazar et al., 2016). For example, BMP9 and BMP10 jointly regulate the production of vasculature (Ricard et al., 2012; Chen et al., 2013), and the existence of heterodimers of BMP2/6, BMP2/ 7 , and BMP4/7 has been confirmed in vivo and in vitro (Bragdon et al., 2011).

BMP2 is a recognized chondrocyte maturation and hypertrophy inducer, and is able to induce cartilage differentiation, osteogenic differentiation, and endochondral ossification of stem cells (Zhou et al., 2016). BMP2's regulation of chondrocyte redifferentiation is controversial in different studies. Davidson observed a lack of articular cartilage hypertrophy in mice overexpressing BMP2 for 6 weeks (Blaney Davidson et al., 2015). In addition, overexpression of BMP2 does not have a significant effect on articular cartilage damage, but it induces extensive osteophyte hyperplasia (Blaney Davidson et al., 2015). Rakic and colleagues combined BMP2 with a Collal small interfering RNA (siRNA) and 3D hypoxia cell culture to induce chondrocyte redifferentiation successfully 


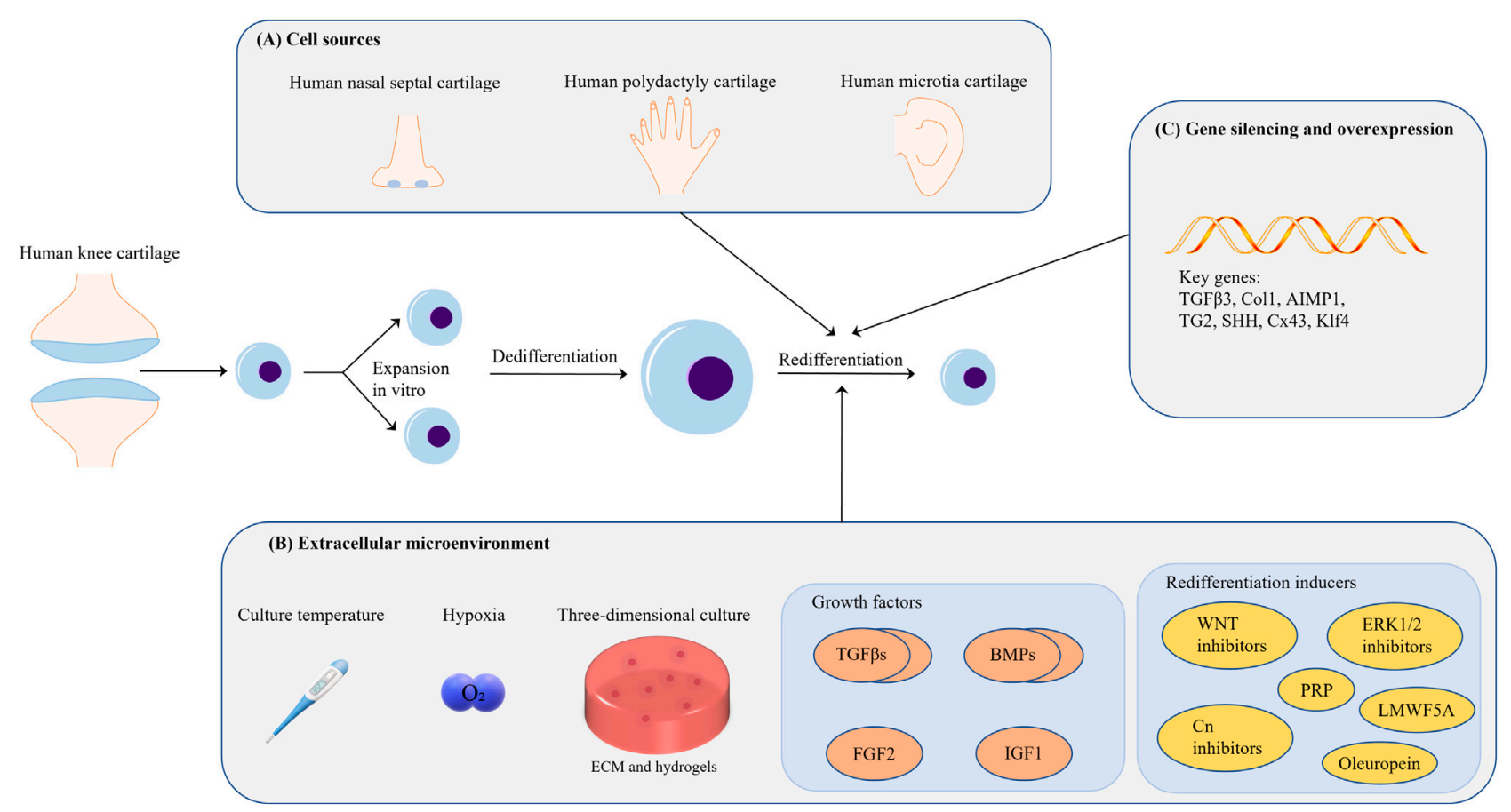

FIGURE 4 | (A) In terms of cell source, it is feasible to use the cartilage tissue from the patient's own diseased joint as a cell source for ACl; chondrogenic diseases such as polydactyly are another potential cell source. (B) Many extracellular environmental factors affect cell redifferentiation; however, proper hypoxia and 3D culture are beneficial for chondrocyte redifferentiation. Hydrogels are the medium used for 3D cell culture, but the related parameter standard of hydrogels warrants further investigation. Members of the TGF- $\beta$ superfamily are currently the most important chondrocyte redifferentiation inducers. The combined application of growth factors may be a good choice in this context. (C) Research on gene silencing and overexpression for the regulation of chondrocyte redifferentiation is still focused on growth-factor-related genes; thus, additional investigation is needed in this area.

(Rakic et al., 2017). It is recognized that the transcription factor RUNX2 can induce bone formation, but the induction into cartilage requires the combined application of transcription factors SOX9 and RUNX2 (Eames et al., 2004). Perhaps similar to the transcription factor RUNX2's role in cartilage formation, BMP2 may be necessary to regulate the redifferentiation of chondrocytes, and the use of BMP2 alone to induce chondrocyte redifferentiation is obviously a wrong method. It is known that BMPs and TGF $\beta$ s are usually combined to participate in the proliferation and differentiation of chondrocytes (Miyamoto et al., 2007; Shintani et al., 2013). The growth factor mixture is a novel approach that is used to modulate the redifferentiation of chondrocytes. A mixture containing TGF $\beta 1$, BMP2, GDF5, BMP6, and fibroblast growth factor 2 (FGF2) has the potential to stably drive cartilage formation (Mendes et al., 2018). Similarly, TGF- $\beta 1$, GDF-5, and BMP-2 as a combined inducer can significantly stimulate the expression of cell cartilage genes and secrete collagen type II (Murphy et al., 2015).

BMP7 promotes the expression of ECM in cartilage. Previous studies have suggested that BMP7 induces heterotopic ossification (Spiro et al., 2010); however, unlike BMP3, BMP7 does not induce excessive osteophyte proliferation (Hunter et al., 2010). The combination therapy of BMP7 and TGF 33 has the advantage to stimulate the redifferentiation of chondrocytes (Huang et al., 2018). In addition, a scaffold composition was able to continuously release BMP7 and TGF $\beta 3$ and promote chondrocyte differentiation (Crecente-Campo et al., 2017). This scaffold can encapsulate a combination of different growth factors and exert a synergistic effect between them, to regulate chondrocyte redifferentiation. An interesting study demonstrated that, after 4 weeks of injection of human synovial MSCs overexpressing BMP7 into the thighs of mice, researchers discovered an implant that histologically resembled a rudimentary joint (Roelofs et al., 2017), in which there was articular cartilage, subchondral bone containing marrow, and a growth plate. This phenomenon warrants further investigation.

The role of BMP4 and BMP6 in the regulation of chondrocyte redifferentiation is poorly understood. BMP4 promotes the secretion of chondrocyte proteoglycan and the expression of collagen type II (Luyten et al., 1994). Similarly, BMP6 promotes the expression of proteoglycan in human cartilage (Bobacz et al., 2003; Chubinskaya et al., 2008). However, a hypertrophic effect of BMP6 has been observed in ATDC5 cells (Ito et al., 1999).

\section{Other Growth Factors}

FGF2 is a growth factor with a wide range of mitogenic and cellsurvival activities (Nawrocka et al., 2020). Adding FGF2 to 
TABLE 2 | Various factors in the extracellular microenvironment modulate the redifferentiation of chondrocytes.

\begin{tabular}{|c|c|c|c|}
\hline Aspects & Factors & Modulation of chondrocyte redifferentiation & References \\
\hline \multirow[t]{8}{*}{$\begin{array}{l}\text { Extracellular } \\
\text { microenvironment }\end{array}$} & Culture temperature & $\begin{array}{l}\text { Culture temperature of } 37^{\circ} \mathrm{C} \text { promotes chondrocyte } \\
\text { redifferentiation }\end{array}$ & von Bomhard et al., (2017); Ito et al., (2015) \\
\hline & Hypoxia & $\begin{array}{l}\text { Hypoxia has a positive effect on the redifferentiation of } \\
\text { chondrocytes }\end{array}$ & $\begin{array}{l}\text { Duval et al., (2009); Markway et al., (2013); Das et al., } \\
\text { (2015); Ollitrault et al., (2015); Rakic et al., (2017); Öztürk } \\
\text { et al., (2017); Jeyakumar et al., (2019) }\end{array}$ \\
\hline & $\begin{array}{l}\text { Three-dimensional } \\
\text { culture }\end{array}$ & $\begin{array}{l}\text { 3D culture has a positive effect on the redifferentiation of } \\
\text { chondrocytes }\end{array}$ & $\begin{array}{l}\text { von Bomhard et al., (2017); He et al., (2020); Caron et al., } \\
\text { (2012); Takahashi et al., (2007); Schulze-Tanzil, (2009); } \\
\text { Mukaida et al., (2005); Ahmed et al., (2014) }\end{array}$ \\
\hline & Hydrogels & $\begin{array}{l}\text { The elasticity of hydrogels, the density of the adhesion } \\
\text { sites, and their configuration methods will all mediate the } \\
\text { redifferentiation of chondrocytes; however, there is } \\
\text { currently a lack of standardized methods for evaluating } \\
\text { hydrogels }\end{array}$ & $\begin{array}{l}\text { Schuh et al., (2012); Zeng et al., (2015); Klotz et al., (2016); } \\
\text { Angelozzi et al., (2017); Bachmann et al., (2020); Öztürk } \\
\text { et al., (2020) }\end{array}$ \\
\hline & ECM & $\begin{array}{l}\text { DCM has a positive effect on the redifferentiation of } \\
\text { chondrocytes, with the disadvantage that it is difficult to } \\
\text { produce in large quantities }\end{array}$ & Pei and He, (2012); Yang et al., (2018); Liang et al., (2020) \\
\hline & $\begin{array}{l}\text { Transforming growth } \\
\text { factor } \beta \text { family }\end{array}$ & $\begin{array}{l}\text { The effect of a single TGF } \beta \text { as an inducer is limited, and the } \\
\text { combined application of multiple TGF } \beta \text { warrants further } \\
\text { research }\end{array}$ & $\begin{array}{l}\text { Jakob et al., (2001); Dong et al., (2005); Lee et al., (2005); } \\
\text { van der Windt et al., (2010); Narcisi et al., (2012); Baugé } \\
\text { et al., (2013); Blaney Davidson et al., (2015); Bianchi et al., } \\
\text { (2017); Crecente-Campo et al., (2017); Roelofs et al., } \\
\text { (2017); Mendes et al., (2018); Bianchi et al., (2019) }\end{array}$ \\
\hline & Other growth factors & $\begin{array}{l}\text { FGF2 and IGF1 induce cell proliferation and } \\
\text { dedifferentiation and, combined with other inducers or } \\
\text { hypoxia, can regulate the redifferentiation of chondrocytes }\end{array}$ & $\begin{array}{l}\text { Martin et al., (2001); Hendriks et al., (2006); Lee et al., } \\
\text { (2017); Witt et al., (2017); Dufour et al., (2019); Endo et al., } \\
\text { (2019); Kikuchi and Shimizu, (2020); Klinder et al., (2020); } \\
\text { Song et al., (2021) }\end{array}$ \\
\hline & $\begin{array}{l}\text { Other redifferentiation } \\
\text { inducers }\end{array}$ & $\begin{array}{l}\text { PRP, LMWF5A, and ERK1/2 inhibitors; WNT inhibitors; Cn } \\
\text { inhibitors and oleuropein all show potential to modulate the } \\
\text { redifferentiation of chondrocytes }\end{array}$ & $\begin{array}{l}\text { van der Windt et al., (2010); Zhong et al., (2016); } \\
\text { Jeyakumar et al., (2017); Hausburg et al., (2018); Wang } \\
\text { et al., (2018); Jeyakumar et al., (2019); Varela-Eirín et al., } \\
\text { (2020) }\end{array}$ \\
\hline
\end{tabular}

chondrocytes cultured in vitro promotes cell proliferation, induces rapid and reversible cell dedifferentiation, and leads to the expression of cartilage marker genes and secretion of ECM after inducing redifferentiation (Jakob et al., 2001; Claus et al., 2012). Several studies have used FGF2 as an inducer to promote the expansion of chondrocytes in vitro (Hendriks et al., 2006; Lee et al., 2017; Endo et al., 2019; Kikuchi and Shimizu, 2020; Song et al., 2021). After a large number of dedifferentiated chondrocytes was obtained, other inducers were used to induce the redifferentiation of chondrocytes (Martin et al., 2001; Dufour et al., 2019). Similarly, hypoxia combined with FGF2 to induce in vitro culture may be a better method for the expansion of chondrocytes in vitro. Moreover, hypoxia combined with FGF2 may improve the growth rate of cells, reduce the level of dedifferentiation during expansion, and have a greater ability to induce redifferentiation (Koh et al., 2017).

The insulin-like growth factor 1 (IGF1) and its downstream pathway play a major role in normal growth and aging, whereas the levels of serum IGF1 decrease with age (Frater et al., 2018). Similar to the role of FGF2, the activation of the IGF1 pathway could drive the rapid proliferation and hypertrophy of chondrocytes (Yakar et al., 2018). Several studies have also confirmed that IGF1 is not conducive to the redifferentiation of chondrocytes (Frerker et al., 2021). However, the combined application of IGF1 and TGF $\beta$ s has been successful in regulating the redifferentiation of chondrocytes (Witt et al., 2017; Klinder et al., 2020).
The vascular endothelial growth factor (VEGF) is involved in angiogenesis and the negative regulation of cartilage growth by stimulating vascular invasion and ossification (Apte et al., 2019). Inhibition of VEGF function has a positive effect on cartilage formation by human-derived nasal chondrocytes (Carlevaro et al., 2000; Medeiros Da Cunha et al., 2017), and the obstruction of vascular invasion during bone healing, rather than osteogenic differentiation, is beneficial to cartilage formation by bone progenitor cells (van Gastel et al., 2020). The relevant researches of growth factors have been summarized and illustrated in Figure 2.

\section{Other Redifferentiation Inducers}

Platelet derivatives (such as platelet-rich plasma (PRP), hyperacute serum (HAS), platelet lysate (PL), and the $<5 \mathrm{kDa}$ fraction of human serum albumin (LMWF5A)) are used to overcome the dedifferentiation caused by the in vitro expansion used to achieve a sufficient number of cells and variable oxygen tension. Recent studies have confirmed that HAS enhances the proliferation of chondrocytes and PRP boosts the proliferation and redifferentiation of dedifferentiated chondrocytes (Jeyakumar et al., 2017; Jeyakumar et al., 2019). The current research on PL supports its application to promote the expansion of chondrocytes; however, there are doubts regarding the regulation of chondrocyte redifferentiation (Rikkers et al., 2020; Liau et al., 2021). Recent studies of LMWF5A have 
shown its potential in inducing fibroblast-like chondrocytes to redifferentiate into functional chondrocytes (Hausburg et al., 2018).

Similarly, inhibitors of several important pathways involved in the regulation of chondrocyte dedifferentiation (such as the MEK-ERK1/2 and WNT signaling pathways) are used to explore their role in the regulation of chondrocyte redifferentiation. The expression of ERK1/2 increases during the process of chondrocyte dedifferentiation, whereas it decreases during the process of redifferentiation. Activation of the MEK-ERK1/2 pathway causes the dedifferentiation of chondrocytes (Provot et al., 2008). PD0325901, which is an inhibitor of ERK1/2, reverses the dedifferentiation and leads to redifferentiation of chondrocytes (Wang et al., 2018). Inhibitors of the WNT signaling pathway, Dickkopf 1 homolog (DKK1), and frizzled-related protein (FRZB), have been shown to be essential for the early steps of chondrocyte differentiation (Zhong et al., 2016). They are necessary for the promotion of the redifferentiation of articular chondrocytes and the inhibition of their hypertrophy and differentiation. Moreover, the activity of calcineurin (Cn) in human articular chondrocytes is significantly increased during dedifferentiation. Therefore, studies of FK506, an inhibitor of $\mathrm{Cn}$, confirmed that it could promote the expression of the chondrogenesis markers collagen type II, proteoglycan, and SOX9 in expanded chondrocytes (van der Windt et al., 2010).

Moreover, the natural plant compound oleuropein is a polyphenol extracted from the leaves and fruits of olives that has been verified to induce the redifferentiation of chondrocytes in patients with osteoarthritis (OA) and to reduce the number of senescent cells in joint tissues (Varela-Eirín et al., 2020). The relevant researches on the extracellular environment have been summarized in Table 2.

\section{GENE SILENCING AND OVEREXPRESSION}

At present, vectors for the overexpression of genes and interfering RNAs have been used in studies of the redifferentiation of chondrocytes. The combined application of a TGF $\beta 3$ adenovirus vector and a Coll short-hairpin RNA (shRNA) promoted the expression of cartilage marker genes in dedifferentiated chondrocytes, such as collagen type II and proteoglycans (Zhang et al., 2011). The siRNA of aminoacyltRNA synthetase-interacting multifunctional protein 1 (AIMP1) restored the TGF $\beta$ signaling pathway in degenerated chondrocytes, thereby enhancing the chondrogenic potential of dedifferentiated chondrocytes (Ahn et al., 2016). Transglutaminase 2 (TG2) is increased in chondrocytes in a passage-dependent manner, and enhances cell dedifferentiation (Eckert et al., 2014). Using TG2 siRNA could lead to the redifferentiation of dedifferentiated chondrocytes by enhancing the glucose metabolism process (Ko et al., 2017). Sonic hedgehog (SHH) is involved in the induction of the early chondrogenic differentiation process of limb mesenchymal cells. The use of an $\mathrm{SHH}$ gene plasmid vector to overexpress dedifferentiated rat chondrocytes increases the expression of $\mathrm{SHH}$ and the synthesis of a variety of cell growth factors (e.g., BMP2 and IGF1). Rats transplanted with SHH-transfected cells show better cartilage repair and induction of the redifferentiation of dedifferentiated chondrocytes (Lin et al., 2014). Connexin43 $(\mathrm{Cx} 43)$ has been validated as a regulator of the transformation between chondrocytes and mesenchymal cells. Downregulation of $\mathrm{Cx} 43$ by CRISPR/Cas9 triggers the redifferentiation of OA chondrocytes (Varela-Eirín et al., 2018). The Kruppel-like factor 4 (Klf4) is a multifunctional transcription factor that regulates diverse cellular processes, such as cell growth, proliferation, and differentiation (Ghaleb and Yang, 2017). The Klf4 gene vector promotes the proliferation and redifferentiation of chondrocytes and inhibits their dedifferentiation (Gurusinghe et al., 2019). The relevant research on the gene expression has been summarized and illustrated in Figure 3.

However, because of ethical issues, the clinical application of gene editing technology remains controversial. Moreover, gene silencing and overexpression do not yield a better effect than do growth factors in regulating the redifferentiation of chondrocytes.

\section{SUMMARY AND PROSPECT}

Articular cartilage is indispensable in the life of all vertebrates. It acts as a buffer against external forces when humans and animals perform various activities. Excessive activity or trauma can cause damage to the articular cartilage, which can lead to restricted movement of the injured joint. Therefore, it is crucial to repair cartilage to restore joint mobility. Cartilage can hardly repair itself, and researchers generally believe that it is due to its extremely poor blood supply and relatively closed intra-articular environment. Researchers had tried to utilize implanting autologous chondrocytes to repair cartilage (Brittberg et al., 1994), but there was no significant effect. Therefore, currently the main clinical treatment for patients with various cartilage injuries suffering from restricted mobility and life disorders is joint replacement surgery. However, the surgical indications for joint replacement surgery determine the limitations of the applicable patients, which can only be used in elderly patients. people. Therefore, repairing cartilage is still the main goal of researchers.

At present, the technical limitation of ACI lies in the low proliferation ability of autologous chondrocytes. After proliferation, chondrocytes will dedifferentiate and lose their cell function, and their ability to synthesize ECM is low. The author believes that the problem is that the extracellular microenvironment for autologous chondrocyte expansion in vitro is very different from the real human in vivo environment. Regardless of the two-dimensional culture, culture medium, extracellular matrix and various extracellular mechanical stimuli are different. Therefore, simulating the extracellular microenvironment of chondrocytes for differentiation and redifferentiation as much as possible may be the fundamental method to solve the technical problems of autologous cartilage implantation. Obviously, this is very difficult in terms of current biological technology. This article summarizes various conditions (cell sources, extracellular environment, growth factors and redifferentiation inducers, and gene silencing and 
overexpression) on the redifferentiation of chondrocytes, hoping to show some surprising progress in this field, and propose a preliminary Strategy (represented in Figure 4).

In summary, the redifferentiation of chondrocytes is modulated at multiple levels. Despite significant progress in this field, many questions remain to be resolved. Regarding the extracellular microenvironment, hypoxia and $3 \mathrm{D}$ culture have shown potential to modulate the redifferentiation of chondrocytes. Although the culture temperature, ECM, and hydrogel all have the effect of modulating the redifferentiation of chondrocytes, they all have their own limitations. For example, a high or low temperature is not conducive to cell expansion, and the amount of naturally generated ECM is limited. There is no doubt that the parameters of the hydrogel also need standardized evaluation criteria. TGF $\beta$ family members are the most used redifferentiation inducers currently. However, they involve complex biological pathways, which renders it difficult to understand the biological effects of a single member of the TGF $\beta$ family. The combined application of different family members may be an appropriate method.

\section{CONCLUSION}

In conclusion, the strategy of regulating the redifferentiation of chondrocytes is not static, it needs to be adjusted according to

\section{REFERENCES}

Ahmed, N., Iu, J., Brown, C. E., Taylor, D. W., and Kandel, R. A. (2014). Serumand Growth-factor-free Three-Dimensional Culture System Supports Cartilage Tissue Formation by Promoting Collagen Synthesis via Sox9-Col2al Interaction. Tissue Eng. Part. A. 20, 2224-2233. doi:10.1089/ten.TEA.2013.0559

Ahn, J., Kumar, H., Cha, B. H., Park, S., Arai, Y., Han, I., et al. (2016). AIMP1 Downregulation Restores Chondrogenic Characteristics of Dedifferentiated/ degenerated Chondrocytes by Enhancing TGF- $\beta$ Signal. Cell Death Dis 7, e2099. doi:10.1038/cddis.2016.17

Angelozzi, M., Penolazzi, L., Mazzitelli, S., Lambertini, E., Lolli, A., Piva, R., et al. (2017). Dedifferentiated Chondrocytes in Composite Microfibers as Tool for Cartilage Repair. Front. Bioeng. Biotechnol. 5, 35. doi:10.3389/fbioe.2017.00035

Antebi, Y. E., Linton, J. M., Klumpe, H., Bintu, B., Gong, M., Su, C., et al. (2017). Combinatorial Signal Perception in the BMP Pathway. Cell 170, 1184-1196.e24. doi:10.1016/j.cell.2017.08.015

Apte, R. S., Chen, D. S., and Ferrara, N. (2019). VEGF in Signaling and Disease: Beyond Discovery and Development. Cell 176, 1248-1264. doi:10.1016/ j.cell.2019.01.021

Bachmann, B., Spitz, S., Schädl, B., Teuschl, A. H., Redl, H., Nürnberger, S., et al. (2020). Stiffness Matters: Fine-Tuned Hydrogel Elasticity Alters Chondrogenic Redifferentiation. Front. Bioeng. Biotechnol. 8, 373. doi:10.3389/ fbioe. 2020.00373

Baugé, C., Duval, E., Ollitrault, D., Girard, N., Leclercq, S., Galéra, P., et al. (2013). Type II TGF $\beta$ Receptor Modulates Chondrocyte Phenotype. Age (Dordr). 35, 1105-1116. doi:10.1007/s11357-012-9433-7

Bianchi, V. J., Lee, A., Anderson, J., Parreno, J., Theodoropoulos, J., Backstein, D., et al. (2019). Redifferentiated Chondrocytes in Fibrin Gel for the Repair of Articular Cartilage Lesions. Am. J. Sports Med. 47, 2348-2359. doi:10.1177/ 0363546519857571

Bianchi, V. J., Weber, J. F., Waldman, S. D., Backstein, D., and Kandel, R. A. (2017). Formation of Hyaline Cartilage Tissue by Passaged Human Osteoarthritic factors such as cell source and cell stage. The ideal strategy for modulating chondrocytes redifferentiation may have 3D culture, hypoxia, appropriate temperature, hydrogel or ECM, inducers suitable for cell expansion phase and cell redifferentiation phase after expansion, respectively. As we continue to learn more about these factors in the future, it will be very important to capitalize on these discoveries by modulating redifferentiation of chondrocytes for the treatment of cartilage damage related diseases.

\section{AUTHOR CONTRIBUTIONS}

$\mathrm{XH}, \mathrm{WZ}$, and XL drafted the manuscript. DZ and YL organized the structure of the manuscript. JL and RJ reviewed the manuscript.

\section{ACKNOWLEDGMENTS}

We acknowledge the Science and Technology Department of Sichuan Province (grant number 2021YJ0473) and National Natural Science Foundation of China (82105027) and Project of the Department of Education of Sichuan Province (grant number 18ZA0195) for the funding of this research. The authors acknowledge the editorial suggestions of SmartStudy Education and Technology Group.

Chondrocytes. Tissue Eng. Part. A. 23, 156-165. doi:10.1089/ ten.TEA.2016.0262

Blaney Davidson, E. N., Remst, D. F., Vitters, E. L., van Beuningen, H. M., Blom, A. B., Goumans, M. J., et al. (2009). Increase in ALK1/ALK5 Ratio as a Cause for Elevated MMP-13 Expression in Osteoarthritis in Humans and Mice. J. Immunol. 182, 7937-7945. doi:10.4049/jimmunol.0803991

Blaney Davidson, E. N., Vitters, E. L., Bennink, M. B., van Lent, P. L., van Caam, A. P., Blom, A. B., et al. (2015). Inducible Chondrocyte-specific Overexpression of BMP2 in Young Mice Results in Severe Aggravation of Osteophyte Formation in Experimental OA without Altering Cartilage Damage. Ann. Rheum. Dis. 74, 1257-1264. doi:10.1136/annrheumdis-2013-204528

Bobacz, K., Gruber, R., Soleiman, A., Erlacher, L., Smolen, J. S., and Graninger, W. B. (2003). Expression of Bone Morphogenetic Protein 6 in Healthy and Osteoarthritic Human Articular Chondrocytes and Stimulation of Matrix Synthesis In Vitro. Arthritis Rheum. 48, 2501-2508. doi:10.1002/art.11248

Bragdon, B., Moseychuk, O., Saldanha, S., King, D., Julian, J., and Nohe, A. (2011). Bone Morphogenetic Proteins: a Critical Review. Cell Signal 23, 609-620. doi:10.1016/j.cellsig.2010.10.003

Brittberg, M., Lindahl, A., Nilsson, A., Ohlsson, C., Isaksson, O., and Peterson, L. (1994). Treatment of Deep Cartilage Defects in the Knee with Autologous Chondrocyte Transplantation. N. Engl. J. Med. 331, 889-895. doi:10.1056/ nejm199410063311401

Carlevaro, M. F., Cermelli, S., Cancedda, R., and Descalzi Cancedda, F. (2000). Vascular Endothelial Growth Factor (VEGF) in Cartilage Neovascularization and Chondrocyte Differentiation: Auto-Paracrine Role during Endochondral Bone Formation. J. Cel Sci 113 (Pt 1), 59-69. doi:10.1080/713803591

Caron, M. M., Emans, P. J., Coolsen, M. M., Voss, L., Surtel, D. A., Cremers, A., et al. (2012). Redifferentiation of Dedifferentiated Human Articular Chondrocytes: Comparison of $2 \mathrm{D}$ and $3 \mathrm{D}$ Cultures. Osteoarthritis Cartilage 20, 1170-1178. doi:10.1016/j.joca.2012.06.016

Cavalli, E., Levinson, C., Hertl, M., Broguiere, N., Brück, O., Mustjoki, S., et al. (2019). Characterization of Polydactyly Chondrocytes and Their 
Use in Cartilage Engineering. Sci. Rep. 9, 4275. doi:10.1038/s41598-01940575-w

Chen, H., Brady Ridgway, J., Sai, T., Lai, J., Warming, S., Chen, H., et al. (2013). Context-dependent Signaling Defines Roles of BMP9 and BMP10 in Embryonic and Postnatal Development. Proc. Natl. Acad. Sci. U S A. 110, 11887-11892. doi:10.1073/pnas.1306074110

Chen, W., and Ten Dijke, P. (2016). Immunoregulation by Members of the TGF $\beta$ Superfamily. Nat. Rev. Immunol. 16, 723-740. doi:10.1038/nri.2016.112

Chubinskaya, S., Segalite, D., Pikovsky, D., Hakimiyan, A. A., and Rueger, D. C. (2008). Effects Induced by BMPS in Cultures of Human Articular Chondrocytes: Comparative Studies. Growth Factors 26, 275-283. doi:10.1080/08977190802291733

Claus, S., Mayer, N., Aubert-Foucher, E., Chajra, H., Perrier-Groult, E., Lafont, J., et al. (2012). Cartilage-characteristic Matrix Reconstruction by Sequential Addition of Soluble Factors during Expansion of Human Articular Chondrocytes and Their Cultivation in Collagen Sponges. Tissue Eng. Part. C Methods 18, 104-112. doi:10.1089/ten.tec.2011.0259

Crecente-Campo, J., Borrajo, E., Vidal, A., and Garcia-Fuentes, M. (2017). New Scaffolds Encapsulating TGF-B3/bmp-7 Combinations Driving strong Chondrogenic Differentiation. Eur. J. Pharm. Biopharm. 114, 69-78. doi:10.1016/j.ejpb.2016.12.021

Das, R., Timur, U. T., Edip, S., Haak, E., Wruck, C., Weinans, H., et al. (2015). TGF$\beta 2$ Is Involved in the Preservation of the Chondrocyte Phenotype under Hypoxic Conditions. Ann. Anat. 198, 1-10. doi:10.1016/j.aanat.2014.11.003

David, C. J., and Massagué, J. (2018). Contextual Determinants of TGF $\beta$ Action in Development, Immunity and Cancer. Nat. Rev. Mol. Cel Biol 19, 419-435. doi:10.1038/s41580-018-0007-0

Dexheimer, V., Gabler, J., Bomans, K., Sims, T., Omlor, G., and Richter, W. (2016). Differential Expression of TGF- $\beta$ Superfamily Members and Role of Smad1/5/ 9-Signalling in Chondral versus Endochondral Chondrocyte Differentiation. Sci. Rep. 6, 36655. doi:10.1038/srep36655

Dong, Y., Drissi, H., Chen, M., Chen, D., Zuscik, M. J., Schwarz, E. M., et al. (2005). Wnt-mediated Regulation of Chondrocyte Maturation: Modulation by TGFBeta. J. Cel Biochem 95, 1057-1068. doi:10.1002/jcb.20466

Dufour, A., Buffier, M., Vertu-Ciolino, D., Disant, F., Mallein-Gerin, F., and Perrier-Groult, E. (2019). Combination of Bioactive Factors and IEIK13 Self-Assembling Peptide Hydrogel Promotes Cartilage Matrix Production by Human Nasal Chondrocytes. J. Biomed. Mater. Res. A. 107, 893-903. doi:10.1002/jbm.a.36612

Duval, E., Leclercq, S., Elissalde, J. M., Demoor, M., Galéra, P., and Boumédiene, K. (2009). Hypoxia-inducible Factor 1alpha Inhibits the Fibroblast-like Markers Type I and Type III Collagen during Hypoxia-Induced Chondrocyte Redifferentiation: Hypoxia Not Only Induces Type II Collagen and Aggrecan, but it Also Inhibits Type I and Type III Collagen in the Hypoxia-Inducible Factor lalpha-dependent Redifferentiation of Chondrocytes. Arthritis Rheum. 60, 3038-3048. doi:10.1002/art.24851

Eames, B. F., Sharpe, P. T., and Helms, J. A. (2004). Hierarchy Revealed in the Specification of Three Skeletal Fates by Sox9 and Runx2. Dev. Biol. 274, 188-200. doi:10.1016/j.ydbio.2004.07.006

Eckert, R. L., Kaartinen, M. T., Nurminskaya, M., Belkin, A. M., Colak, G., Johnson, G. V., et al. (2014). Transglutaminase Regulation of Cell Function. Physiol. Rev. 94, 383-417. doi:10.1152/physrev.00019.2013

Endo, K., Fujita, N., Nakagawa, T., and Nishimura, R. (2019). Effect of Fibroblast Growth Factor-2 and Serum on Canine Mesenchymal Stem Cell Chondrogenesis. Tissue Eng. Part. A. 25, 901-910. doi:10.1089/ten.TEA.2018.0177

Frater, J., Lie, D., Bartlett, P., and McGrath, J. J. (2018). Insulin-like Growth Factor 1 (IGF-1) as a Marker of Cognitive Decline in normal Ageing: A Review. Ageing Res. Rev. 42, 14-27. doi:10.1016/j.arr.2017.12.002

Frerker, N., Karlsen, T. A., Lilledahl, M. B., Brorson, S. H., Tibballs, J. E., and Brinchmann, J. E. (2021). Scaffold-Free Engineering of Human Cartilage Implants. Cartilage, 19476035211007923. doi:10.1177/19476035211007923

Freyria, A. M., and Mallein-Gerin, F. (2012). Chondrocytes or Adult Stem Cells for Cartilage Repair: the Indisputable Role of Growth Factors. Injury 43, 259-265. doi:10.1016/j.injury.2011.05.035

Ghaleb, A. M., and Yang, V. W. (2017). Krüppel-like Factor 4 (KLF4): What We Currently Know. Gene 611, 27-37. doi:10.1016/j.gene.2017.02.025

Gurusinghe, S., Bandara, N., Hilbert, B., Trope, G., Wang, L., and Strappe, P. (2019). Lentiviral Vector Expression of Klf4 Enhances Chondrogenesis and
Reduces Hypertrophy in Equine Chondrocytes. Gene 680, 9-19. doi:10.1016/ j.gene.2018.09.013

Han, X., Chang, S., Zhang, M., Bian, X., Li, C., and Li, D. (2021). Advances of Hydrogel-Based Bioprinting for Cartilage Tissue Engineering. Front. Bioeng. Biotechnol. 9, 746564. doi:10.3389/fbioe.2021.746564

Hausburg, M. A., Frederick, E. D., McNair, P., Schwappach, J., Banton, K. L., Roshon, M., et al. (2018). Clinically Relevant Redifferentiation of Fibroblast-like Chondrocytes into Functional Chondrocytes by the Low Molecular Weight Fraction of Human Serum Albumin. Clin. Exp. Rheumatol. 36, 891-895.

He, A., Ye, A., Song, N., Liu, N., Zhou, G., Liu, Y., et al. (2020). Phenotypic Redifferentiation of Dedifferentiated Microtia Chondrocytes through a ThreeDimensional Chondrogenic Culture System. Am. J. Transl Res. 12, 2903-2915.

Hendriks, J., Riesle, J., and Vanblitterswijk, C. A. (2006). Effect of Stratified Culture Compared to Confluent Culture in Monolayer on Proliferation and Differentiation of Human Articular Chondrocytes. Tissue Eng. 12, 2397-2405. doi:10.1089/ten.2006.12.2397

Huang, X., Zhong, L., Post, J. N., and Karperien, M. (2018). Co-treatment of TGFB3 and BMP7 Is superior in Stimulating Chondrocyte Redifferentiation in Both Hypoxia and Normoxia Compared to Single Treatments. Sci. Rep. 8, 10251. doi:10.1038/s41598-018-27602-y

Hunter, D. J., Pike, M. C., Jonas, B. L., Kissin, E., Krop, J., and McAlindon, T. (2010). Phase 1 Safety and Tolerability Study of BMP-7 in Symptomatic Knee Osteoarthritis. BMC Musculoskelet. Disord. 11, 232. doi:10.1186/1471-2474$11-232$

Ito, A., Aoyama, T., Iijima, H., Tajino, J., Nagai, M., Yamaguchi, S., et al. (2015). Culture Temperature Affects Redifferentiation and Cartilaginous Extracellular Matrix Formation in Dedifferentiated Human Chondrocytes. J. Orthop. Res. 33, 633-639. doi:10.1002/jor.22808

Ito, H., Akiyama, H., Shigeno, C., and Nakamura, T. (1999). Bone Morphogenetic Protein- 6 and Parathyroid Hormone-Related Protein Coordinately Regulate the Hypertrophic Conversion in Mouse Clonal Chondrogenic EC Cells, ATDC5. Biochim. Biophys. Acta 1451, 263-270. doi:10.1016/s0167-4889(99) 00100-7

Jahr, H., Gunes, S., Kuhn, A. R., Nebelung, S., and Pufe, T. (2019). BioreactorControlled Physoxia Regulates TGF- $\beta$ Signaling to Alter Extracellular Matrix Synthesis by Human Chondrocytes. Int. J. Mol. Sci. 20, 715. doi:10.3390/ ijms 20071715

Jakob, M., Démarteau, O., Schäfer, D., Hintermann, B., Dick, W., Heberer, M., et al. (2001). Specific Growth Factors during the Expansion and Redifferentiation of Adult Human Articular Chondrocytes Enhance Chondrogenesis and Cartilaginous Tissue Formation In Vitro. J. Cel Biochem 81, 368-377. doi:10.1002/1097-4644(20010501)81:2<368:aid-jcb1051>3.0.co;2-j

Jeyakumar, V., Niculescu-Morzsa, E., Bauer, C., Lacza, Z., and Nehrer, S. (2017). Platelet-Rich Plasma Supports Proliferation and Redifferentiation of Chondrocytes during In Vitro Expansion. Front. Bioeng. Biotechnol. 5, 75. doi:10.3389/fbioe.2017.00075

Jeyakumar, V., Niculescu-Morzsa, E., Bauer, C., Lacza, Z., and Nehrer, S. (2019). Redifferentiation of Articular Chondrocytes by Hyperacute Serum and Platelet Rich Plasma in Collagen Type I Hydrogels. Int. J. Mol. Sci. 20, 316. doi:10.3390/ ijms 20020316

Jones, D. G., and Peterson, L. (2006). Autologous Chondrocyte Implantation. J. Bone Jt. Surg Am 88, 2502-2520. doi:10.2106/00004623-200611000-00025

Kikuchi, T., and Shimizu, T. (2020). Thickness-wise Growth Technique for Human Articular Chondrocytes to Fabricate Three-Dimensional Cartilage Grafts. Regen. Ther. 14, 119-127. doi:10.1016/j.reth.2019.12.001

Kim, K. O., Sampson, E. R., Maynard, R. D., O'Keefe, R. J., Chen, D., Drissi, H., et al. (2012). Ski Inhibits TGF-B/phospho-Smad3 Signaling and Accelerates Hypertrophic Differentiation in Chondrocytes. J. Cel Biochem 113, 2156-2166. doi:10.1002/jcb.24089

Klinder, A., Kussauer, S., Hiemer, B., Wree, A., Bader, R., and Jonitz-Heincke, A. (2020). Influence of Conditioned Media on the Re-differentiation Capacity of Human Chondrocytes in 3D Spheroid Cultures. J. Clin. Med. 9, 2798. doi: $10.3390 / \mathrm{jcm} 9092798$

Klotz, B. J., Gawlitta, D., Rosenberg, A. J. W. P., Malda, J., and Melchels, F. P. W. (2016). Gelatin-Methacryloyl Hydrogels: Towards Biofabrication-Based Tissue Repair. Trends Biotechnol. 34, 394-407. doi:10.1016/j.tibtech.2016.01.002

Ko, K. W., Choi, B., Park, S., Arai, Y., Choi, W. C., Lee, J. M., et al. (2017). DownRegulation of Transglutaminase 2 Stimulates Redifferentiation of 
Dedifferentiated Chondrocytes through Enhancing Glucose Metabolism. Int. J. Mol. Sci. 18, 2359. doi:10.3390/ijms 18112359

Koh, S., Purser, M., Wysk, R., and Piedrahita, J. A. (2017). Improved Chondrogenic Potential and Proteomic Phenotype of Porcine Chondrocytes Grown in Optimized Culture Conditions. Cell Reprogram 19, 232-244. doi:10.1089/ cell.2017.0005

Krishnan, Y., and Grodzinsky, A. J. (2018). Cartilage Diseases. Matrix Biol. 71-72, 51-69. doi:10.1016/j.matbio.2018.05.005

Lee, D. K., Choi, K. B., Oh, I. S., Song, S. U., Hwang, S., Lim, C. L., et al. (2005). Continuous Transforming Growth Factor Betal Secretion by Cell-Mediated Gene Therapy Maintains Chondrocyte Redifferentiation. Tissue Eng. 11, 310-318. doi:10.1089/ten.2005.11.310

Lee, J., Lee, J. Y., Chae, B. C., Jang, J., Lee, E., and Son, Y. (2017). Fully Dedifferentiated Chondrocytes Expanded in Specific Mesenchymal Stem Cell Growth Medium with FGF2 Obtains Mesenchymal Stem Cell Phenotype In Vitro but Retains Chondrocyte Phenotype In Vivo. Cel Transpl. 26, 1673-1687. doi:10.1177/0963689717724794

Li, T. F., Darowish, M., Zuscik, M. J., Chen, D., Schwarz, E. M., Rosier, R. N., et al. (2006). Smad3-deficient Chondrocytes Have Enhanced BMP Signaling and Accelerated Differentiation. J. Bone Miner Res. 21, 4-16. doi:10.1359/ jbmr.050911

Liang, Y., Szojka, A. R. A., Idrees, E., Kunze, M., Mulet-Sierra, A., and Adesida, A. B. (2020). Re-Differentiation of Human Meniscus Fibrochondrocytes Differs in ThreeDimensional Cell Aggregates and Decellularized Human Meniscus Matrix Scaffolds. Ann. Biomed. Eng. 48, 968-979. doi:10.1007/s10439-019-02272-7

Liau, L. L., Hassan, M. N. F. B., Tang, Y. L., Ng, M. H., and Law, J. X. (2021). Feasibility of Human Platelet Lysate as an Alternative to Foetal Bovine Serum for In Vitro Expansion of Chondrocytes. Int. J. Mol. Sci. 22, 1269. doi:10.3390/ijms22031269

Lin, L., Shen, Q., Xue, T., Duan, X., Fu, X., and Yu, C. (2014). Sonic Hedgehog Improves Redifferentiation of Dedifferentiated Chondrocytes for Articular Cartilage Repair. PLoS One 9, e88550. doi:10.1371/journal.pone.0088550

Lorda-Diez, C. I., Montero, J. A., Choe, S., Garcia-Porrero, J. A., and Hurle, J. M. (2014). Ligand- and Stage-dependent Divergent Functions of BMP Signaling in the Differentiation of Embryonic Skeletogenic Progenitors In Vitro. J. Bone Miner Res. 29, 735-748. doi:10.1002/jbmr.2077

Luyten, F. P., Chen, P., Paralkar, V., and Reddi, A. H. (1994). Recombinant Bone Morphogenetic Protein-4, Transforming Growth Factor-Beta 1, and Activin A Enhance the Cartilage Phenotype of Articular Chondrocytes In Vitro. Exp. Cel Res 210, 224-229. doi:10.1006/excr.1994.1033

Makris, E. A., Gomoll, A. H., Malizos, K. N., Hu, J. C., and Athanasiou, K. A. (2015). Repair and Tissue Engineering Techniques for Articular Cartilage. Nat. Rev. Rheumatol. 11, 21-34. doi:10.1038/nrrheum.2014.157

Markway, B. D., Cho, H., and Johnstone, B. (2013). Hypoxia Promotes Redifferentiation and Suppresses Markers of Hypertrophy and Degeneration in Both Healthy and Osteoarthritic Chondrocytes. Arthritis Res. Ther. 15, R92. doi:10.1186/ar4272

Martin, I., Suetterlin, R., Baschong, W., Heberer, M., Vunjak-Novakovic, G., and Freed, L. E. (2001). Enhanced Cartilage Tissue Engineering by Sequential Exposure of Chondrocytes to FGF-2 during 2D Expansion and BMP-2 during 3D Cultivation. J. Cel Biochem 83, 121-128. doi:10.1002/jcb.1203

Medeiros Da Cunha, C. M., Perugini, V., Bernegger, P., Centola, M., Barbero, A., Guildford, A. L., et al. (2017). Vascular Endothelial Growth Factor Sequestration Enhances In Vivo Cartilage Formation. Int. J. Mol. Sci. 18, 2478. doi:10.3390/ijms18112478

Mendes, L. F., Katagiri, H., Tam, W. L., Chai, Y. C., Geris, L., Roberts, S. J., et al. (2018). Advancing Osteochondral Tissue Engineering: Bone Morphogenetic Protein, Transforming Growth Factor, and Fibroblast Growth Factor Signaling Drive Ordered Differentiation of Periosteal Cells Resulting in Stable Cartilage and Bone Formation In Vivo. Stem Cel Res Ther 9, 42. doi:10.1186/s13287-018-0787-3

Minas, T., Von Keudell, A., Bryant, T., and Gomoll, A. H. (2014). The John Insall Award: A Minimum 10-year Outcome Study of Autologous Chondrocyte Implantation. Clin. Orthop. Relat. Res. 472, 41-51. doi:10.1007/s11999-013-3146-9

Mistry, H., Connock, M., Pink, J., Shyangdan, D., Clar, C., Royle, P., et al. (2017). Autologous Chondrocyte Implantation in the Knee: Systematic Review and Economic Evaluation. Health Technol. Assess. 21, 1-294. doi:10.3310/hta21060 Miyamoto, C., Matsumoto, T., Sakimura, K., and Shindo, H. (2007). Osteogenic Protein-1 with Transforming Growth Factor-Betal: Potent Inducer of
Chondrogenesis of Synovial Mesenchymal Stem Cells In Vitro. J. Orthop. Sci. 12, 555-561. doi:10.1007/s00776-007-1176-4

Mukaida, T., Urabe, K., Naruse, K., Aikawa, J., Katano, M., Hyon, S. H., et al. (2005). Influence of Three-Dimensional Culture in a Type II Collagen Sponge on Primary Cultured and Dedifferentiated Chondrocytes. J. Orthop. Sci. 10, 521-528. doi:10.1007/s00776-005-0930-8

Mumme, M., Barbero, A., Miot, S., Wixmerten, A., Feliciano, S., Wolf, F., et al. (2016). Nasal Chondrocyte-Based Engineered Autologous Cartilage Tissue for Repair of Articular Cartilage Defects: an Observational First-In-Human Trial. Lancet 388, 1985-1994. doi:10.1016/s0140-6736(16)31658-0

Murphy, M. K., Huey, D. J., Hu, J. C., and Athanasiou, K. A. (2015). TGF- $\beta 1$, GDF5 , and BMP-2 Stimulation Induces Chondrogenesis in Expanded Human Articular Chondrocytes and Marrow-Derived Stromal Cells. Stem Cells 33, 762-773. doi:10.1002/stem.1890

Narcisi, R., Signorile, L., Verhaar, J. A., Giannoni, P., and van Osch, G. J. (2012). TGF $\beta$ Inhibition during Expansion Phase Increases the Chondrogenic Redifferentiation Capacity of Human Articular Chondrocytes. Osteoarthritis Cartilage 20, 1152-1160. doi:10.1016/j.joca.2012.06.010

Nawrocka, D., Krzyscik, M. A., Opaliński, Ł., Zakrzewska, M., and Otlewski, J. (2020). Stable Fibroblast Growth Factor 2 Dimers with High Pro-survival and Mitogenic Potential. Int. J. Mol. Sci. 21, 4108. doi:10.3390/ijms21114108

Ollitrault, D., Legendre, F., Drougard, C., Briand, M., Benateau, H., Goux, D., et al. (2015). BMP-2, Hypoxia, and COL1A1/HtrA1 siRNAs Favor Neo-Cartilage Hyaline Matrix Formation in Chondrocytes. Tissue Eng. Part. C Methods 21, 133-147. doi:10.1089/ten.TEC.2013.0724

Öztürk, E., Hobiger, S., Despot-Slade, E., Pichler, M., and Zenobi-Wong, M. (2017). Hypoxia Regulates RhoA and Wnt/ $\beta$-Catenin Signaling in a Contextdependent Way to Control Re-differentiation of Chondrocytes. Sci. Rep. 7, 9032. doi:10.1038/s41598-017-09505-6

Öztürk, E., Stauber, T., Levinson, C., Cavalli, E., Arlov, Ø., and Zenobi-Wong, M. (2020). Tyrosinase-crosslinked, Tissue Adhesive and Biomimetic Alginate Sulfate Hydrogels for Cartilage Repair. Biomed. Mater. 15, 045019. doi:10.1088/1748-605X/ab8318

Pei, M., and He, F. (2012). Extracellular Matrix Deposited by Synovium-Derived Stem Cells Delays Replicative Senescent Chondrocyte Dedifferentiation and Enhances Redifferentiation. J. Cel Physiol 227, 2163-2174. doi:10.1002/ jcp. 22950

Provot, S., Nachtrab, G., Paruch, J., Chen, A. P., Silva, A., and Kronenberg, H. M. (2008). A-raf and B-Raf Are Dispensable for normal Endochondral Bone Development, and Parathyroid Hormone-Related Peptide Suppresses Extracellular Signal-Regulated Kinase Activation in Hypertrophic Chondrocytes. Mol. Cel Biol 28, 344-357. doi:10.1128/mcb.00617-07

Rakic, R., Bourdon, B., Hervieu, M., Branly, T., Legendre, F., Saulnier, N., et al. (2017). RNA Interference and BMP-2 Stimulation Allows Equine Chondrocytes Redifferentiation in 3D-Hypoxia Cell Culture Model: Application for Matrix-Induced Autologous Chondrocyte Implantation. Int. J. Mol. Sci. 18, 1842. doi:10.3390/ijms18091842

Rédini, F., Mauviel, A., Pronost, S., Loyau, G., and Pujol, J. P. (1993). Transforming Growth Factor Beta Exerts Opposite Effects from Interleukin-1 Beta on Cultured Rabbit Articular Chondrocytes through Reduction of Interleukin-1 Receptor Expression. Arthritis Rheum. 36, 44-50. doi:10.1002/art.1780360108

Ricard, N., Ciais, D., Levet, S., Subileau, M., Mallet, C., Zimmers, T. A., et al. (2012). BMP9 and BMP10 Are Critical for Postnatal Retinal Vascular Remodeling. Blood 119, 6162-6171. doi:10.1182/blood-2012-01-407593

Rikkers, M., Levato, R., Malda, J., and Vonk, L. A. (2020). Importance of Timing of Platelet Lysate-Supplementation in Expanding or Redifferentiating Human Chondrocytes for Chondrogenesis. Front. Bioeng. Biotechnol. 8, 804. doi:10.3389/fbioe.2020.00804

Roelofs, A. J., Zupan, J., Riemen, A. H. K., Kania, K., Ansboro, S., White, N., et al. (2017). Joint Morphogenetic Cells in the Adult Mammalian Synovium. Nat. Commun. 8, 15040. doi:10.1038/ncomms15040

Salazar, V. S., Gamer, L. W., and Rosen, V. (2016). BMP Signalling in Skeletal Development, Disease and Repair. Nat. Rev. Endocrinol. 12, 203-221. doi:10.1038/ nrendo.2016.12

Schuh, E., Hofmann, S., Stok, K., Notbohm, H., Müller, R., and Rotter, N. (2012). Chondrocyte Redifferentiation in 3D: the Effect of Adhesion Site Density and Substrate Elasticity. J. Biomed. Mater. Res. A. 100, 38-47. doi:10.1002/jbm.a.33226 
Schulze-Tanzil, G. (2009). Activation and Dedifferentiation of Chondrocytes: Implications in Cartilage Injury and Repair. Ann. Anat. 191, 325-338. doi:10.1016/j.aanat.2009.05.003

Shintani, N., Siebenrock, K. A., and Hunziker, E. B. (2013). TGF-B1 Enhances the BMP-2-Induced Chondrogenesis of Bovine Synovial Explants and Arrests Downstream Differentiation at an Early Stage of Hypertrophy. PLoS One 8, e53086. doi:10.1371/journal.pone.0053086

Smolen, J. S., Aletaha, D., and McInnes, I. B. (2016). Rheumatoid Arthritis. Lancet 388, 2023-2038. doi:10.1016/s0140-6736(16)30173-8

Song, H., Du, H., Li, J., Wang, M., Wang, J., Ju, X., et al. (2021). Effect of Fibroblast Growth Factor 2 on Degenerative Endplate Chondrocyte: From Anabolism to Catabolism. Exp. Mol. Pathol. 118, 104590. doi:10.1016/j.yexmp.2020.104590

Spiro, A. S., Beil, F. T., Baranowsky, A., Barvencik, F., Schilling, A. F., Nguyen, K., et al. (2010). BMP-7-induced Ectopic Bone Formation and Fracture Healing Is Impaired by Systemic NSAID Application in C57BL/6-Mice. J. Orthop. Res. 28, 785-791. doi:10.1002/jor.21044

Stegen, S., Laperre, K., Eelen, G., Rinaldi, G., Fraisl, P., Torrekens, S., et al. (2019). HIF-1 $\alpha$ Metabolically Controls Collagen Synthesis and Modification in Chondrocytes. Nature 565, 511-515. doi:10.1038/s41586-019-0874-3

Takahashi, N., Rieneck, K., van der Kraan, P. M., van Beuningen, H. M., Vitters, E. L., Bendtzen, K., et al. (2005). Elucidation of IL-1/TGF-beta Interactions in Mouse Chondrocyte Cell Line by Genome-wide Gene Expression. Osteoarthritis Cartilage 13, 426-438. doi:10.1016/j.joca.2004.12.010

Takahashi, T., Ogasawara, T., Asawa, Y., Mori, Y., Uchinuma, E., Takato, T., et al. (2007). Three-dimensional Microenvironments Retain Chondrocyte Phenotypes during Proliferation Culture. Tissue Eng. 13, 1583-1592. doi: $10.1089 /$ ten.2006.0322

Thielen, N. G. M., van der Kraan, P. M., and van Caam, A. P. M. (2019). TGF $\beta /$ BMP Signaling Pathway in Cartilage Homeostasis. Cells 8. doi:10.3390/ cells8090969

van der Kraan, P., Vitters, E., and van den Berg, W. (1992). Differential Effect of Transforming Growth Factor Beta on Freshly Isolated and Cultured Articular Chondrocytes. J. Rheumatol. 19, 140-145. doi:10.1002/art.1780350126

van der Windt, A. E., Jahr, H., Farrell, E., Verhaar, J. A., Weinans, H., and van Osch, G. J. (2010). Calcineurin Inhibitors Promote Chondrogenic Marker Expression of Dedifferentiated Human Adult Chondrocytes via Stimulation of Endogenous TGFbetal Production. Tissue Eng. Part. A. 16, 1-10. doi:10.1089/ten.TEA.2009.0082 van Gastel, N., Stegen, S., Eelen, G., Schoors, S., Carlier, A., Daniëls, V. W., et al. (2020). Lipid Availability Determines Fate of Skeletal Progenitor Cells via SOX9. Nature 579, 111-117. doi:10.1038/s41586-020-2050-1

Varela-Eirín, M., Carpintero-Fernández, P., Sánchez-Temprano, A., VarelaVázquez, A., Paíno, C. L., Casado-Díaz, A., et al. (2020). Senolytic Activity of Small Molecular Polyphenols from Olive Restores Chondrocyte Redifferentiation and Promotes a Pro-regenerative Environment in Osteoarthritis. Aging (Albany NY) 12, 15882-15905. doi:10.18632/aging.103801

Varela-Eirín, M., Varela-Vázquez, A., Guitián-Caamaño, A., Paíno, C. L., Mato, V., Largo, R., et al. (2018). Targeting of Chondrocyte Plasticity via Connexin 43 Modulation Attenuates Cellular Senescence and Fosters a Pro-regenerative Environment in Osteoarthritis. Cel Death Dis 9, 1166. doi:10.1038/s41419-018-1225-2

Vega, S. L., Kwon, M. Y., and Burdick, J. A. (2017). Recent Advances in Hydrogels for Cartilage Tissue Engineering. Eur. Cel Mater 33, 59-75. doi:10.22203/eCM.v033a05 von Bomhard, A., Faust, J., Elsaesser, A. F., Schwarz, S., Pippich, K., and Rotter, N. (2017). Impact of Expansion and Redifferentiation under Hypothermia on Chondrogenic Capacity of Cultured Human Septal Chondrocytes. J. Tissue Eng. 8, 2041731417732655. doi:10.1177/2041731417732655

Wang, X., Xue, Y., Ye, W., Pang, J., Liu, Z., Cao, Y., et al. (2018). The MEK-Erk1/2 Signaling Pathway Regulates Hyaline Cartilage Formation and the
Redifferentiation of Dedifferentiated Chondrocytes In Vitro. Am. J. Transl Res. 10, 3068-3085.

Witt, A., Salamon, A., Boy, D., Hansmann, D., Büttner, A., Wree, A., et al. (2017). Gene Expression Analysis of Growth Factor Receptors in Human Chondrocytes in Monolayer and 3D Pellet Cultures. Int. J. Mol. Med. 40, 10-20. doi:10.3892/ ijmm.2017.2994

Wozney, J. M., Rosen, V., Celeste, A. J., Mitsock, L. M., Whitters, M. J., Kriz, R. W., et al. (1988). Novel Regulators of Bone Formation: Molecular Clones and Activities. Science 242, 1528-1534. doi:10.1126/science.3201241

Wu, J., Liyarita, B. R., Zhu, H., Liu, M., Hu, X., and Shao, F. (2021b). Self-Assembly of Dendritic DNA into a Hydrogel: Application in Three-Dimensional Cell Culture. ACS Appl. Mater. Inter. 13, 49705. doi:10.1021/acsami.1c14445

Wu, X., Su, J., Wei, J., Jiang, N., and Ge, X. (2021a). Recent Advances in ThreeDimensional Stem Cell Culture Systems and Applications. Stem Cell Int 2021, 9477332. doi:10.1155/2021/9477332

Yakar, S., Werner, H., and Rosen, C. J. (2018). Insulin-like Growth Factors: Actions on the Skeleton. J. Mol. Endocrinol. 61, T115-t137. doi:10.1530/jme-17-0298

Yang, X., Chen, L., Xu, X., Li, C., Huang, C., and Deng, C. X. (2001). TGF-beta/Smad3 Signals Repress Chondrocyte Hypertrophic Differentiation and Are Required for Maintaining Articular Cartilage. J. Cel Biol 153, 35-46. doi:10.1083/jcb.153.1.35

Yang, Y., Lin, H., Shen, H., Wang, B., Lei, G., and Tuan, R. S. (2018). Mesenchymal Stem Cell-Derived Extracellular Matrix Enhances Chondrogenic Phenotype of and Cartilage Formation by Encapsulated Chondrocytes In Vitro and In Vivo. Acta Biomater. 69, 71-82. doi:10.1016/j.actbio.2017.12.043

Zeng, L., Chen, X., Zhang, Q., Yu, F., Li, Y., and Yao, Y. (2015). Redifferentiation of Dedifferentiated Chondrocytes in a Novel Three-Dimensional Microcavitary Hydrogel. J. Biomed. Mater. Res. A. 103, 1693-1702. doi:10.1002/jbm.a.35309

Zhang, F., Yao, Y., Su, K., Pang, P. X., Zhou, R., Wang, Y., et al. (2011). Redifferentiation of Dedifferentiated Chondrocytes by Adenoviral VectorMediated TGF-B3 and Collagen-1 Silencing shRNA in 3D Culture. Ann. Biomed. Eng. 39, 3042-3054. doi:10.1007/s10439-011-0398-y

Zhong, L., Huang, X., Rodrigues, E. D., Leijten, J. C., Verrips, T., El Khattabi, M., et al. (2016). Endogenous DKK1 and FRZB Regulate Chondrogenesis and Hypertrophy in Three-Dimensional Cultures of Human Chondrocytes and Human Mesenchymal Stem Cells. Stem Cell Dev 25, 1808-1817. doi:10.1089/ scd.2016.0222

Zhou, N., Li, Q., Lin, X., Hu, N., Liao, J. Y., Lin, L. B., et al. (2016). BMP2 Induces Chondrogenic Differentiation, Osteogenic Differentiation and Endochondral Ossification in Stem Cells. Cell Tissue Res 366, 101-111. doi:10.1007/s00441016-2403-0

Conflict of Interest: The authors declare that the research was conducted in the absence of any commercial or financial relationships that could be construed as a potential conflict of interest.

Publisher's Note: All claims expressed in this article are solely those of the authors and do not necessarily represent those of their affiliated organizations, or those of the publisher, the editors and the reviewers. Any product that may be evaluated in this article, or claim that may be made by its manufacturer, is not guaranteed or endorsed by the publisher.

Copyright $\odot 2021 \mathrm{Hu}$, Zhang, Li, Zhong, Li, Li and Jin. This is an open-access article distributed under the terms of the Creative Commons Attribution License (CC BY). The use, distribution or reproduction in other forums is permitted, provided the original author(s) and the copyright owner(s) are credited and that the original publication in this journal is cited, in accordance with accepted academic practice. No use, distribution or reproduction is permitted which does not comply with these terms. 